Plant Tissue Cult. \& Biotech. 30(2): 219-229, 2020 (December)

(CBangladesh Assoc. for Plant Tissue Culture \& Biotechnology

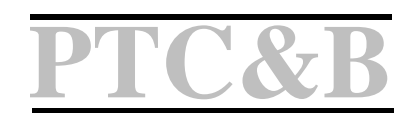

\title{
High Efficiency In vitro Regeneration and Genetic Stability of Corallocarpus epigaeus - An Endangered Medicinal Plant
}

\section{Spoorthi Veera, Pavani Chirumamilla ${ }^{1}$ and Shasthree Taduri*}

Department of Biotechnology, Kakatiya University, Warangal-506009, TS, India

Keywords: High Efficiency, In vitro regeneration, Multiple shoots, Genetic fidelity, ISSR

\begin{abstract}
Indirect regeneration of plantlets from multiple shoot induction of Corallocarpus epigaeus was obtained from leaf and nodal explants on MS with different concentrations of BAP in combination with IAA ABA or IBA alone. Among all the combinations, BAP and IBA exhibited maximum regeneration. High frequency of multiple shoots $(89 \%)$ was obtained on BAP $(2.0 \mathrm{mg} \Lambda)$ and IBA $(1.5 \mathrm{mg} \Lambda)$ in nodal explants. Maximum mean shoot length of $6.8 \pm 0.33 \mathrm{~cm}$ was obtained in nodal explants cultured on BAP $(1.0 \mathrm{mg} \Lambda)+\operatorname{IBA}(0.5 \mathrm{mg} /)$, followed by leaf explants with $6.7 \pm 0.47 \mathrm{~cm}$ on BAP $(3.0 \mathrm{mg} \Lambda)+$ IAA $(2.5 \mathrm{mg} \Lambda)$. The highest frequency of rooting $(88.3 \%)$ was obtained on NAA $(1.0 \mathrm{mg} \Lambda)$ and IBA $(2.0 \mathrm{mg} /)$ with $21.83 \pm 0.57$ mean number of roots. The well-rooted healthy plantlets were acclimatized with a survival rate of $80 \%$. Inter simple sequence repeat (ISSR) analysis revealed the genetic similarity of in vitro raised plants with the mother plant.
\end{abstract}

\section{Introduction}

Corallocarpus epigaeus, a medicinal endangered tuberous climber belongs to Cucurbitaceae. It is a monoecious climber. This species is globally distributed in tropical Africa, and southeast Asia. In India it has been recorded from Punjab, Madhya Pradesh, West Bengal, Bihar, Uttar Pradesh, Telangana and Andhra Pradesh (Umadevi and Kamalam 2012). C. epigaeus is commonly called as Akas Gaddah. C. epigaeus plant is one such important medicinal plants used in treating syphilitis, venereal complaints and chronic dysentery (Kothawade and Siddiqui 2018); it is also effectively used to cure diabetes (Gnananath et al. 2013), snakebites (Chandrakala et al. 2013) and rheumatism (Uthrapathy et al. 2011).

*Author for correspondence: : <shastritaduri@gmail.com>. ${ }^{1}$ Department of Biotechnology, Singareni Collieries Women's Degree \& PG College, Kothagudem-507101, TS, India.

DOI: https://doi.org/10.3329/ptcb.v30i2.50692 
It also possesses anthelmintic property (Kirubha et al. 2011), anti-fertility (Dhanapal et al. 2006), haematopoietic (Saranya et al. 2017), hepatoprotective (Mahesh et al. 2012), antioxidant and anti-inflammatory (Jeyaseelan et al. 2014) activities.

The medicinal value of plants contains some chemical substances, usually secondary metabolites, which produce a definite physiological action on the human body. As per the above reason, it is very essential for conservation and in vitro propagation. The in vitro propagation studies were carried out in C. epigaeus for protection of species with the help of leaf and node explants, due to lack of a suitable method for natural regeneration and over-exploitation of C. epigaeus, which severely deteriorated the species consequently recording them as endangered species (Vemula et al. 2020). Due to exploitative harvesting of tubers for trade and denudation of forests, the natural population of $C$. epigaeus has declined to such an extent that it is now considered rare and threatened in its natural habitats (Narayan 2016).

Screening of genetic fidelity is also important to study the genetic variations in in vitro regenerated plants with the parents. The somaclonal variations may occur due to explant type, phytohormones, and subsequent subculturing during micropropagation (Lakshmanan et al. 2007). ISSR molecular markers are used to screen total plant genome coding and non-coding sequences and discover the genetic variations (Collard and Mackill 2009). The present study reveals the high frequency of in vitro regeneration and genetic fidelity analysis of regenerated plants of $C$. epigaeus. Further, it is necessary to design in vitro acclimatized plantlet roots by treating with bio-inoculates (PGPR, Azotobacter, PSM and Mycorrhiza) for evaluating their survival rate in abiotic stress conditions.

\section{Materials and Methods}

The tuberous root of Corallocarpus epigaeus was collected from Asifabad Forest, Telangana State, India during monsoon season. The plants were grown and maintained at departmental greenhouse, Department of Biotechnology, Kakatiya University, Telangana State, India. Young leaves and nodes were collected, washed thoroughly and subsequently surfaced sterilized with $2 \%(\mathrm{w} / \mathrm{N})$ Tween-20 (for microbial disinfection) for 3 - $4 \mathrm{~min}$, then rinsed with distilled water for 3 - 4 times. The explants were transferred to laminar airflow for further sterilization. The explants (leaf and node segments) were sterilized with $0.1 \%(\mathrm{w} / \mathrm{N}) \mathrm{HgCl}_{2}$ for $2-3 \mathrm{~min}$ and then rinsed again with sterilized distilled water to remove any traces of $\mathrm{HgCl}_{2}$.

MS provided with sucrose ( $3 \%$ ) and myo-inositol (100 $\mathrm{mg} \Lambda$ ) was used throughout the study. The $\mathrm{pH}$ was adjusted to 5.7 with $0.1 \mathrm{~N} \mathrm{NaOH}$ or $0.1 \mathrm{~N} \mathrm{HCl}$ and addition of agar $(0.8 \%)$ resulted in the solidification of the medium. The medium was sterilized at $121^{\circ} \mathrm{C}$ for 15 min under 15 psi pressure. The surface sterilized leaf and nodal explants were inoculated and maintained at $25 \pm 2^{\circ} \mathrm{C}$ under a $16 / 8 \mathrm{hrs}$ light and dark cycle provided by cool fluorescent tubes. 
The explants cultured on MS with different concentrations of BAP in combination with IAA/BA or IBA alone induced callus and upon subculturing induced multiple shoots from callus. Regularly, the cultures were subcultured onto the fresh medium for 4-5 weeks intervals. The observations were made every six days of inoculation. All the experiments were conducted thrice with 60 explants for each treatment. The rate of multiplication represents the number of shoots produced per explant on a specific medium after the number of days of its inoculation as mentioned in the results. Data were collected and analyzed after 45 days.

The individual in vitro raised multiple shoots developed from calli were excised and subcultured onto half-strength MS including plant growth regulators IBANAA/AA alone (at a concentration of $0.2-1.5 \mathrm{mg} \Lambda$ ) for adventitious roots. The data on the number of roots and root length were recorded after 3 weeks. The significant differences with different parameters recorded were calculated by mean and standard error variance (ANOVA) using SPSS software.

After 3 weeks of root initiation, plantlets were collected and rinsed with sterile distilled water to remove the traces of nutrient medium. Plantlets were transplanted into the pots containing sterile black soil, peat, and sand $(2: 1: 1)$ (Fig. 2e,f). The pots were covered with transparent polythene covers to maintain the growth conditions and humidity of about $70-80 \%$, light $60 \mu \mathrm{mol} / \mathrm{m}^{2} / \mathrm{s}$, at $25 \pm 2^{\circ} \mathrm{C}$. These transplanted plants were kept in the culture room and irrigated every alternate day with sterile water for three weeks. After three weeks of hardening, the plantlets were exposed to the field and transferred to greenhouse for further acclimatization.

Assessment of genetic fidelity of C. epigaeus plants was made through ISSR analysis. Genomic DNA was isolated from the mother plant and regenerated plantlets by C-TAB method (Doyle and Doyle 1987) and amplified by PCR using ISSR primers. Three ISSR primers (Hy2: AGAGAGAGAGAGAGAGG, Hy3: TCTCTCTCTCTCTCTCG, and Hy5: AGAGAGAGAGAGAGAGYT) were chosen from 8 tested primers based on their compatibility (Table 3). Using these three primers, mother plant and in vitro regenerated plants' DNA were amplified in PCR, conditions following (initial denaturation $94^{\circ} \mathrm{C}$ for $5^{\prime}, 30$ cycles of $94^{\circ} \mathrm{C} 30 \mathrm{Sec}, 50^{\circ} \mathrm{C} 30 \mathrm{Sec}, 72^{\circ} \mathrm{C}$ for $1 \mathrm{~min}$ followed by final extension of $72^{\circ} \mathrm{C}$ for $7^{\prime}$ ) and chemicals used for the PCR reaction were from Fermentas, Maryland, USA. Amplified PCR products were examined by agarose gel electrophoresis (1\%) and photographed using Gel Doc XR+ (Bio-Rad).

\section{Results and Discussion}

The explants cultured on basal MS without any plant growth regulators (PGRs) had no morphogenetic response of either callus or multiple shoot induction. The leaf and nodal explants cultured onto MS with varying concentrations of BAP + IAA, BAP + IBA and IBA alone induced callus from the cut ends of the explants. Excessive green callus was obtained on MS augmented with IBA $(1.0 \mathrm{mg} \Lambda)$ from both leaf and nodal explants (Figs 
$1 b, 2 b)$, whereas in the previous studies reported in the same plant, quick callus growth was obtained on MS with BA (2.0 mg $\Lambda$ ) and NAA (0.5 mg $\Lambda)$ from stem and leaf explants (Narayan 2016). Similar results of green callusing on MS with IBA was obtained in Gossypium hirsutum, where IBA (1.5 $\mathrm{mg} /$ ) achieved $86.6 \%$ of green callus (Abdellatef and Khalafallah 2008) and in Jatropha curcas IBA induced green callus which later turned brown (Rajore and Batra 2007). But in contrast,a high percentage of callogenesis and excessive green callusing was achieved in Citrullus colocynthis on $\mathrm{Kn}$ and TDZ supplemented medium (Dasari et al. 2015).
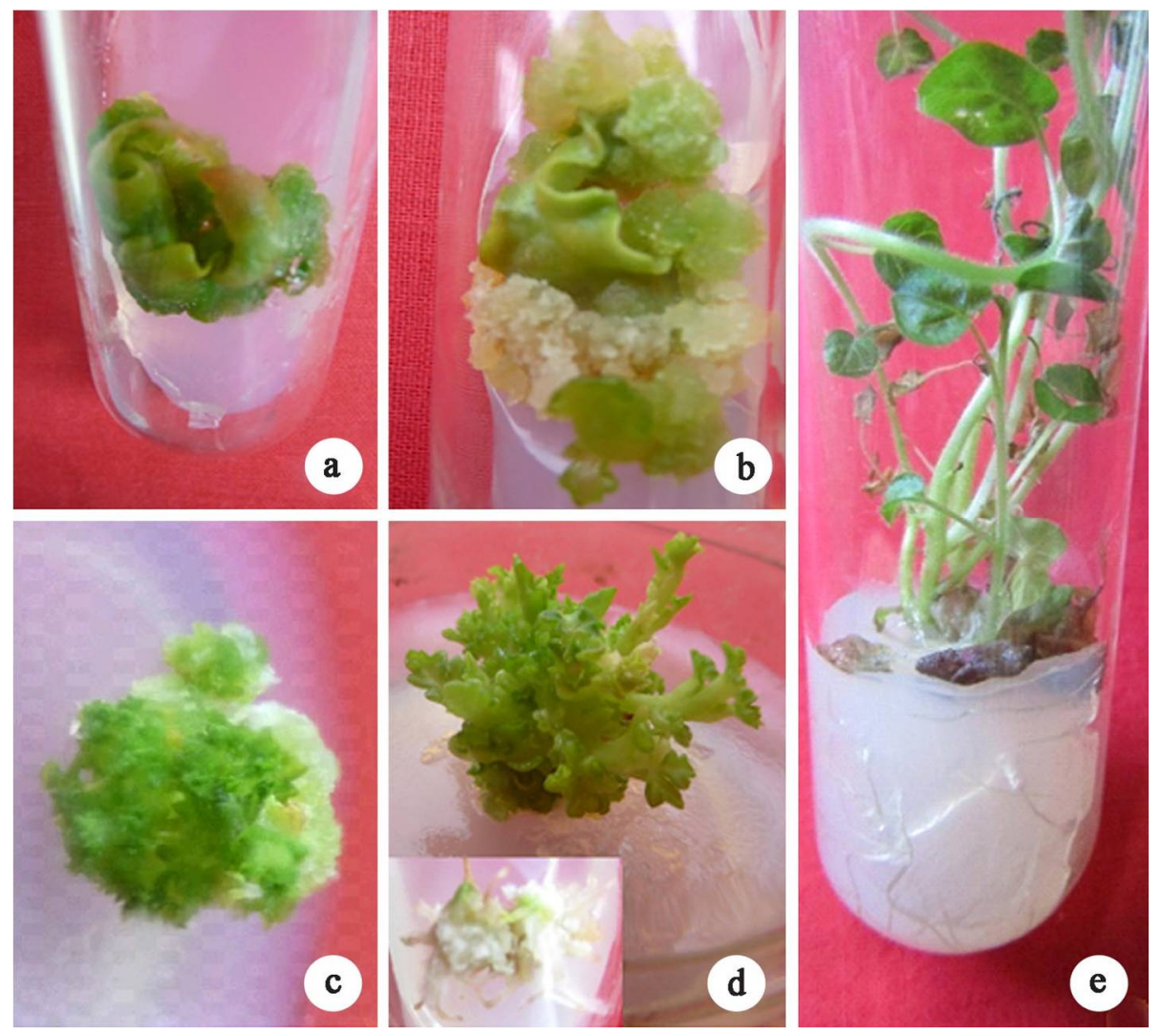

Fig.1. Effect of PGRs on indirect plant regeneration from leaf explants of Corallocarpus epigaeus. a. Initiation of callus on $1.0 \mathrm{mg} /$ IBA. b. Profusely induction of light green callus on MS with $1.0 \mathrm{mg} / \mathrm{IBA}$. c. Initiation of micro-shoots at $1.5 \mathrm{mg} / \mathrm{IAA}$ and $2.0 \mathrm{mg} / \mathrm{BAP}$. d. Formation of multiple shoots and elongation on $1.5 \mathrm{mg} /$ IBA and $2.0 \mathrm{mg} / \mathrm{BAP}$ (rooting was shown in insight). e. High frequency of multiple shoots with roots was formed on MS with $1.5 \mathrm{mg} / \mathrm{IAA}$ and $2.0 \mathrm{mg} / \mathrm{BAP}$.

The same callus was subcultured on half-strength MS with the same plant growth regulators. Among all the combinations and concentrations, IBA + BAP was found to be efficient. High regeneration frequency of multiple shoots $(89.33 \%)$ was obtained in nodal explants, followed by leaf explants $(86.00 \%)$ on MS with IBA $(1.5 \mathrm{mg} \Lambda)$ and BAP $(2.0$ 
$\mathrm{mg} /$ ). The optimum mean number of shoots $(15.7 \pm 0.81$ and $13.8 \pm 0.95)$ was obtained in nodal and leaf explants on the same medium (Figs 1d, $2 \mathrm{c}$ and Table 1). The maximum mean shoot length of $6.8 \pm 0.39 \mathrm{~cm}$ was obtained on IBA $(0.5 \mathrm{mg} \Lambda)$ and BAP $(1.0 \mathrm{mg} \Lambda)$ in nodal explants (Fig. 2d), whereas the maximum shoot length of $6.7 \pm 0.47 \mathrm{~cm}$ was obtained on MS with IAA (2.5 mg 1$)$ and BAP (3.0 mg $/)$ in leaf explants (Fig. 1e and Table 1).

Table 1. Effect of PGR's on node and leaf explants of Corallocarpus epigaeus in the induction of multiple shoots.

\begin{tabular}{|c|c|c|c|c|c|c|c|}
\hline \multicolumn{2}{|c|}{$\begin{array}{l}\text { PGR's conc. } \\
\quad(\mathrm{mg} \Lambda)\end{array}$} & \multicolumn{2}{|c|}{ Regeneration } & \multicolumn{2}{|c|}{$\begin{array}{l}\text { Mean no. of } \\
\text { shoots } \pm \text { SE }\end{array}$} & \multicolumn{2}{|c|}{$\begin{array}{c}\text { Mean shoot } \\
\text { length }(\mathrm{cm}) \pm \mathrm{SE}\end{array}$} \\
\hline & & Node & Leaf & Node & Leaf & Node & Leaf \\
\hline \multicolumn{8}{|l|}{ IBA } \\
\hline 0.5 & & $68.33 \pm 0.39$ & $64.23 \pm 0.29$ & $6.3 \pm 0.6$ & $5.9 \pm 0.3$ & $5.5 \pm 0.47$ & $5.3 \pm 0.34$ \\
\hline 1.0 & & $75.67 \pm 0.65$ & $73.37 \pm 0.97$ & $7.2 \pm 0.5$ & $7.1 \pm 0.5$ & $5.1 \pm 0.43$ & $4.7 \pm 0.40$ \\
\hline 1.5 & & $77.37 \pm 0.14$ & $76.33 \pm 0.51$ & $13.1 \pm 0.8$ & $12.2 \pm 0.6$ & $3.3 \pm 0.28$ & $3.2 \pm 0.36$ \\
\hline 2.0 & & $78.0 \pm 0.25$ & $79.13 \pm 0.68$ & $12.4 \pm 0.9$ & $11.3 \pm 0.4$ & $4.2 \pm 0.39$ & $4.1 \pm 0.45$ \\
\hline 2.5 & & $66.67 \pm 0.53$ & $70.33 \pm 0.14$ & $8.5 \pm 0.38$ & $9.4 \pm 0.51$ & $4.7 \pm 0.20$ & $4.3 \pm 0.37$ \\
\hline \multicolumn{8}{|c|}{$\mathrm{IAA}+\mathrm{BAP}$} \\
\hline 0.5 & 1.0 & $67.33 \pm 0.74$ & $66.67 \pm 0.37$ & $5.2 \pm 0.61$ & $5.1 \pm 0.71$ & $6.5 \pm 0.63$ & $6.4 \pm 0.37$ \\
\hline 1.0 & 1.5 & $74.67 \pm 0.90$ & $73.33 \pm 0.83$ & $8.3 \pm 0.20$ & $7.9 \pm 0.29$ & $4.3 \pm 0.37$ & $5.5 \pm 0.25$ \\
\hline 1.5 & 2.0 & $85.67 \pm 0.14$ & $84.0 \pm 0.25$ & $12.5 \pm 0.87$ & $11.4 \pm 0.8$ & $3.4 \pm 0.56$ & $3.6 \pm 0.35$ \\
\hline 2.0 & 2.5 & $75.33 \pm 0.23$ & $76.27 \pm 0.53$ & $9.2 \pm 0.41$ & $9.4 \pm 0.32$ & $4.1 \pm 0.29$ & $4.5 \pm 0.40$ \\
\hline 2.5 & 3.0 & $65.0 \pm 0.1$ & $65.78 \pm 0.75$ & $4.3 \pm 0.72$ & $4.8 \pm 0.91$ & $5.4 \pm 0.42$ & $6.7 \pm 0.47$ \\
\hline \multicolumn{8}{|c|}{$\mathrm{IBA}+\mathrm{BAP}$} \\
\hline 0.5 & 1.0 & $67.37 \pm 0.53$ & $66.37 \pm 0.90$ & $6.3 \pm 0.37$ & $6.2 \pm 0.39$ & $6.8 \pm 0.39$ & $5.8 \pm 0.57$ \\
\hline 1.0 & 1.5 & $76.67 \pm 0.14$ & $75.27 \pm 0.65$ & $7.8 \pm 0.31$ & $9.6 \pm 0.29$ & $5.3 \pm 0.40$ & $4.9 \pm 0.63$ \\
\hline 1.5 & 2.0 & $89.33 \pm 0.39$ & $86.0 \pm 0.78$ & $15.7 \pm 0.81$ & $13.8 \pm 0.9$ & $3.2 \pm 0.54$ & $3.4 \pm 0.45$ \\
\hline 2.0 & 2.5 & $76.43 \pm 0.97$ & $73.0 \pm 0.51$ & $11.7 \pm 0.63$ & $7.9 \pm 0.38$ & $4.0 \pm 0.47$ & $5.4 \pm 0.29$ \\
\hline 2.5 & 3.0 & $65.0 \pm 0.77$ & $67.32 \pm 0.29$ & $8.7 \pm 0.44$ & $6.9 \pm 0.49$ & $5.9 \pm 0.35$ & $6.2 \pm 0.44$ \\
\hline
\end{tabular}

However, the regeneration studies carried out previously in the same plant showed the maximum percentage response of 68.33 on BA $(0.5 \mathrm{mg} \Lambda)+\mathrm{IAA}(2.0 \mathrm{mg} \Lambda)$ (Narayan 2016) and 88 on TDZ (1.5 mg $\Lambda)$ + IAA (1.5 mg $\Lambda$ ) (Vemula et al. 2020). The combination of IBA and BAP was also found to be effective in species like Bryonopsis lacinosa, where IBA and BAP induced multiple shoots from cotyledon derived callus (Caroline and Mallaiah 2011), whereas in Cicer arietinum, IBA and BAP resulted in maximum percentage of response in all explants (Sadhu et al. 2020). But in contrast, only BAP alone induced 
multiple shoot regeneration in several plants like Cucurbita pepo and Beninca sahispida (Haque et al. 2008), Momordica dioica (Devendra et al. 2009), lentils (Ozdemir and Turker 2014), Ficus (Hesami et al. 2018) and Cucumis sativa (Venkatachalam et al. 2018).
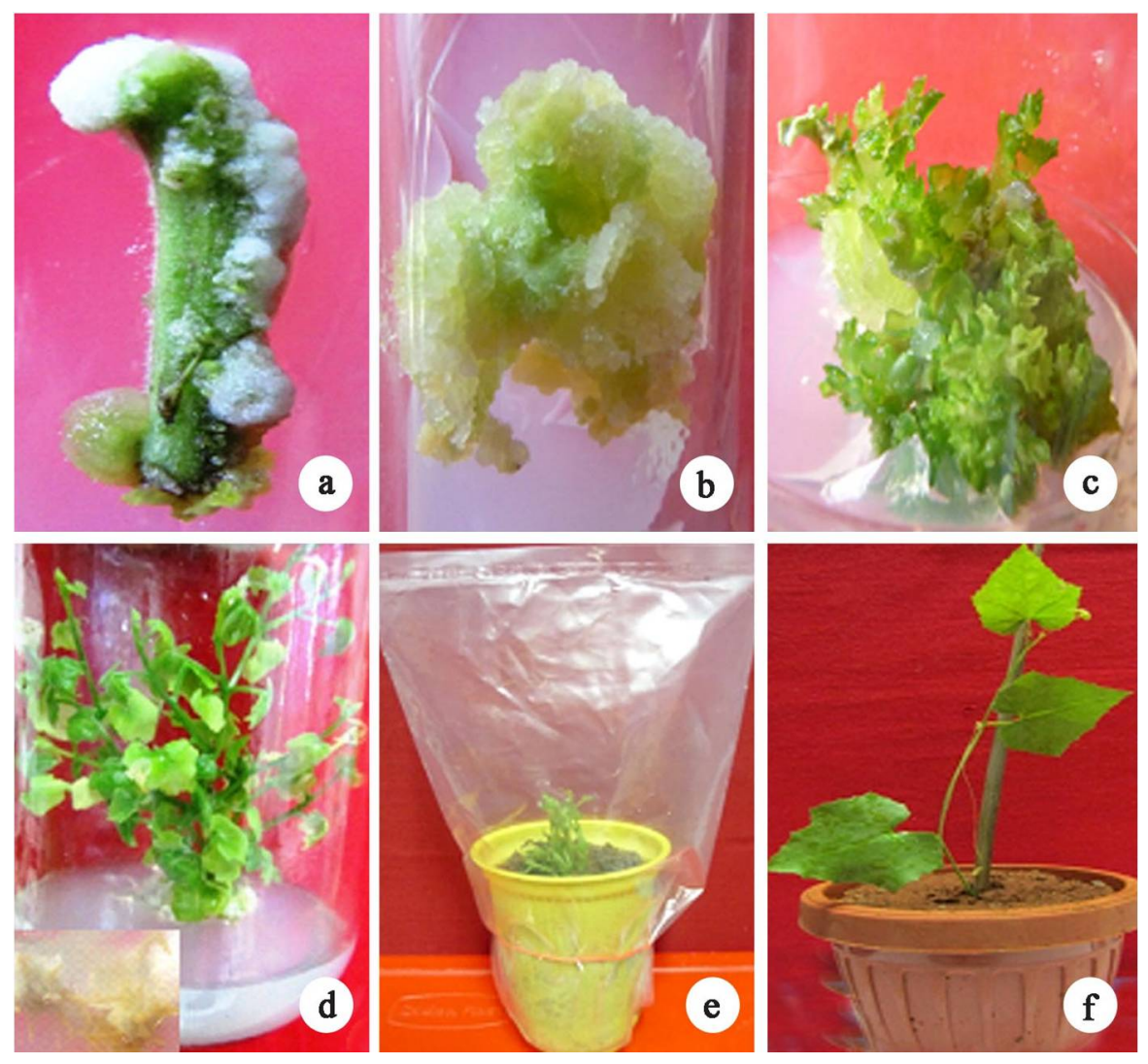

Fig. 2. In vitro regeneration of Corallocarpus epigaeus from nodal explants. a. Initiation of callus from mature nodal explants. b. Induction of complete light green callus from nodal explants. c. Initiation and proliferation of multiple shoots from light greenish callus. d. Elongated multiple shoots transferred to rooting medium (rooting was shown in insight). e. In vitro regenerated plantlets. f. Partially hardened plants.

The combination of BAP and IAA showed less regeneration in C. epigaeus when compared to other combinations. Present results do not agree with the reports of other plants, where BAP and IAA induced adventitious shoots in Beninca sahispida (He et al. 2006) and high concentration of BAP and IAA induced shoot regeneration in Citrullus boulgaris (Dong and Jia 1991). BAP and IAA also induced multiple shoot regeneration in Anisochilus cornosus (Reshi et al. 2017), Bambusa glaucescens (Shirin and Rana 2007), and Lagenaria siceraria (Saha et al. 2007).

The highest frequency of rooting $(88.3 \pm 0.14)$ was obtained on MS with NAA (1.0 $\mathrm{mg} \Lambda)$ and IBA $(2.0 \mathrm{mg} \Lambda)$ with $21.83 \pm 0.57$ mean number of roots from nodal explants and 
$19.36 \pm 0.22$ from leaf explants. The highest mean root length of $5.6 \pm 0.62 \mathrm{~cm}$ was obtained on NAA $(0.5 \mathrm{mg} /)$ and IBA $(1.0 \mathrm{mg} /)$ from leaf explants and $5.2 \pm 0.45 \mathrm{~cm}$ on IBA $(1.5 \mathrm{mg} \Lambda)$ in nodal explants (Table 2). Similar results were obtained in Citrullus colocynthis, where NAA and IBA, IAA and IBA showed the best rooting (Krishna and Shasthree 2015). Kumar et al. (2003) also reported similar results in Cucumis sativa and NAA and IBA proved to be best for callus induction as well as rooting from leaf and stem explants of Heliotropium indicum (Bagadekar and Jayaraj 2011).

Table 2. Effect of various PGRs in induction of roots of Corallocarpus epigaeus.

\begin{tabular}{|c|c|c|c|c|c|c|}
\hline \multirow[t]{2}{*}{$\begin{array}{l}\text { PGR's conc. } \\
\quad(\mathrm{mg} \Lambda)\end{array}$} & \multicolumn{2}{|c|}{$\begin{array}{c}\% \text { of culture } \\
\text { producing roots }\end{array}$} & \multicolumn{2}{|c|}{$\begin{array}{c}\text { Mean no. of } \\
\text { roots } \pm \text { SE }\end{array}$} & \multicolumn{2}{|c|}{$\begin{array}{c}\text { Mean length } \\
\text { of roots }(\mathrm{cm}) \pm \mathrm{SE}\end{array}$} \\
\hline & Node & Leaf & Node & Leaf & Node & Leaf \\
\hline \multicolumn{7}{|l|}{ IBA } \\
\hline 0.2 & $68.3 \pm 0.83$ & $77.0 \pm 0.51$ & $5.67 \pm 0.74$ & $5.36 \pm 0.42$ & $3.6 \pm 0.33$ & $3.4 \pm 0.46$ \\
\hline 0.5 & $75.6 \pm 0.74$ & $84.3 \pm 0.78$ & $6.12 \pm 0.51$ & $7.22 \pm 0.31$ & $2.8 \pm 0.41$ & $1.8 \pm 0.32$ \\
\hline 1.0 & $86.0 \pm 0.51$ & $65.6 \pm 0.39$ & $7.44 \pm 0.39$ & $4.96 \pm 0.34$ & $1.9 \pm 0.44$ & $3.9 \pm 0.49$ \\
\hline 1.5 & $66.0 \pm 0.68$ & $55.0 \pm 0.25$ & $4.92 \pm 0.48$ & $3.49 \pm 0.45$ & $5.2 \pm 0.45$ & $4.9 \pm 0.61$ \\
\hline \multicolumn{7}{|l|}{ NAA } \\
\hline 0.2 & $67.0 \pm 0.25$ & $75.0 \pm 0.25$ & $4.92 \pm 0.19$ & $5.41 \pm 0.75$ & $3.8 \pm 0.25$ & $3.2 \pm 0.49$ \\
\hline 0.5 & $76.3 \pm 0.29$ & $80.6 \pm 0.39$ & $6.51 \pm 0.47$ & $6.49 \pm 0.52$ & $2.5 \pm 0.66$ & $2.6 \pm 0.88$ \\
\hline 1.0 & $82.0 \pm 0.77$ & $63.6 \pm 0.65$ & $7.0 \pm 0.25$ & $5.63 \pm 0.34$ & $1.8 \pm 0.53$ & $3.1 \pm 0.75$ \\
\hline 1.5 & $74.6 \pm 0.74$ & $51.6 \pm 0.29$ & $5.43 \pm 0.55$ & $4.54 \pm 0.48$ & $2.7 \pm 0.23$ & $4.4 \pm 0.66$ \\
\hline \multicolumn{7}{|l|}{$\mathrm{NAA}+\mathrm{IBA}$} \\
\hline $0.5+1.0$ & $65.4 \pm 0.62$ & $63.4 \pm 0.32$ & $13.46 \pm 0.86$ & $11.32 \pm 0.36$ & $5.1 \pm 0.82$ & $5.6 \pm 0.62$ \\
\hline $0.5+2.0$ & $68.6 \pm 0.25$ & $66.2 \pm 0.74$ & $15.91 \pm 0.92$ & $14.21 \pm 0.29$ & $4.2 \pm 0.51$ & $4.5 \pm 0.76$ \\
\hline $1.0+1.0$ & $77.3 \pm 0.90$ & $75.1 \pm 0.83$ & $18.55 \pm 0.66$ & $16.29 \pm 0.44$ & $4.7 \pm 0.56$ & $3.9 \pm 0.69$ \\
\hline $1.0+2.0$ & $88.3 \pm 0.14$ & $87.0 \pm 0.35$ & $21.83 \pm 0.57$ & $19.36 \pm 0.22$ & $3.3 \pm 0.44$ & $3.5 \pm 0.40$ \\
\hline
\end{tabular}

ISSR markers were used to assess the genetic fidelity between the mother plant and the regenerated plants of $C$. epigaeus plants. A similar kind of genetic fidelity evaluation was successfully obtained in different plant systems like Citrullus colocynthis (Dasari et al. 2015), Mentha arvensis (Faisal et al. 2014), Corallocarpus epigaeus (Vemula et al. 2020), Momoridica cymbalaria (Chaitanya et al. 2020), Ocimum tenuiflorum (Aggarwal et al. 2020), Cicer arietinum (Sadhu et al. 2020) and Sapium sebiferum (Hou et al. 2020) using ISSR assessment. The ISSR analysis confirmed that there is no polymorphic nature between regenerated and mother plants, both plants exhibited similar monomorphic banding patterns ranged between $100 \mathrm{bp}$ and $2.5 \mathrm{~kb}$. Therefore, the results showed that the mother plant and regenerated plant contain the same gene pool (Fig. 3 and Table 3). ISSR analysis revealed the genetic stability of in vitro raised plants with the mother plant. 
The present study demonstrated an efficient regeneration protocol through indirect organogenesis using leaf and node explants of Corallocarpus epigaeus and assessment of genetic fidelity demonstrates the true-to-type nature of regenerated plants comparatively to the mother plant. The combination of BAP $(2.0 \mathrm{mg} \Lambda)$ and IBA $(1.5 \mathrm{mg} \Lambda)$ were shown to be best for maximum regeneration of $89.33 \%$ with $15.7 \pm 0.81$ mean number of shoots in nodal explants. The highest mean shoot of $6.8 \pm 0.39 \mathrm{~cm}$ was obtained at IBA $(0.5 \mathrm{mg} \Lambda)$

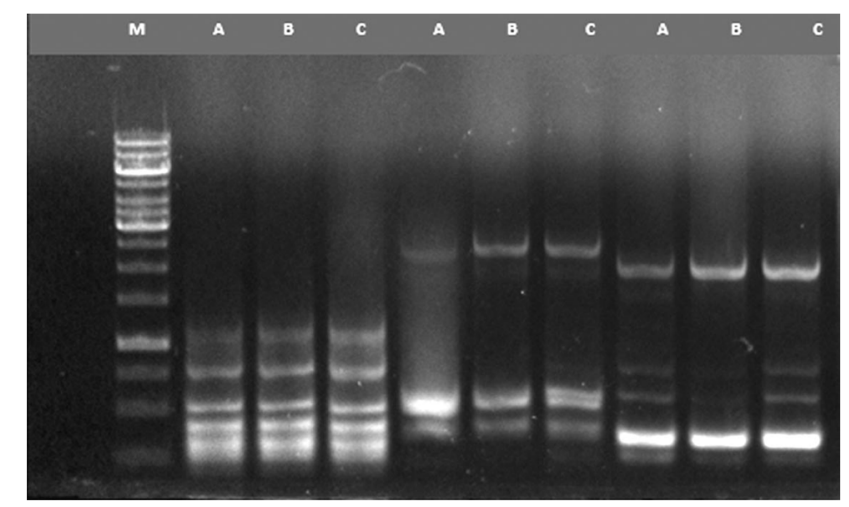

Fig. 3. Genetic fidelity of regenerated plantlets. $\mathrm{M}=$ Marker, $\mathrm{A}=$ Mother plant, B-C = Regenerated plantlets.

Table. 3. Genetic fidelity of in vitro regenerated plantlets using 3 different primers.

\begin{tabular}{cccc}
\hline Sl. no. & Primers & Primer sequence & Size of the band \\
\hline 1 & Hy2 & AGAGAGAGAGAGAGAGG & $100-1 \mathrm{~kb}$ \\
2 & Hy3 & TCTCTCTCTCTCTCTCG & $500-2.5 \mathrm{~kb}$ \\
3 & Hy5 & AGAGAGAGAGAGAGAGYT & $100-2.0 \mathrm{~kb}$ \\
\hline
\end{tabular}

and BAP $(1.0 \mathrm{mg} \Lambda)$ in nodal explants and $6.7 \pm 0.47$ in leaf explants on MS with IAA (2.5 $\mathrm{mg} \Lambda$ ) and BAP $(3.0 \mathrm{mg} \Lambda)$. The induced shoots transferred to half-strength MS with NAA/ IBA/NAA and IBA for rooting, better results were shown at $1.0 \mathrm{mg} \Lambda$ NAA and $2.0 \mathrm{mg} \Lambda$ IBA with a maximum mean number of roots of $21.83 \pm 0.57$ in nodal explants. Further in vitro regenerated acclimatized plantlets are using for isolating and screening of secondary metabolites from various plant parts. For the above reasons, biotechnological analysis studies are required in C. epigaeus.

\section{Acknowledgments}

The authors are thankful to the Department of Biotechnology, Kakatiya University, Warangal, Telangana State, India for providing facilities. 


\section{References}

Abdellatef E and Khalafallah MM (2008) Influence of growth regulators on callus induction from hypocotyls of medium staple cotton (Gossypium hirsutum L.) Cultivar barac B-67. Journal of Soil Nature 2(1): 17-22.

Aggarwal D, Neeti N, Reddy MS and Kumar A (2020) Shoot organogenesis and assessment of clonal fidelity of regenerated plants of Ocimum tenuiflorum L. queen of Herbs. Vegetos 33: 420429.https://doi.org/10.1007/\$42535-020-00124-7.

Bagadekar AN and Jayaraj M (2011) In vitro rhizogenesis from leaf and stem callus of Heliotropium indicum. Medicinal Herb. 2: 1-5.

Caroline V and Mallaiah B (2011) High frequency in vitro rhizogenesis in Bryonopsis laciniosa (L.) Naud. a highly valuable medicinal cucurbit. Int. J. Pharm. Bio Sci. 2.1: 216-223.

Chaitanya G, Chandra Shekar Ch, PavaniCh, Suvarchala V and Shasthree T(2020) Rapid in vitro adventitious rooting and proliferation by leaf and nodal cultures of Momordica cymbalaria Fenzl. Journal of Applied Biology \& Biotechnology 8(02): 103-107.

Chandrakala AN, Harinatha RA, Nageswari G, Vani Sri DS, Shabana Begum S and Venkatappa B (2013) Anti-Venom and immunomodulatory Functions of Corallocarpu sepigaeus L. Int. J. Pharm. Biol. Sci. 4(1): 654-60.

Collard BCY and Mackill DJ (2009) Conserved DNA-derived polymorphism (CDDP): A simple and novel method for generating DNA markers in plants. Plant Mol. Biol. Rep. 27: 558-562.

DasariR, Narra M, Ellendula R, Kota S and Taduri S (2015) Efficient in vitro propagation system via multiple hoot induction and assessment of Clonal fidelity of regenerants in Citrullus colocynthis (L.) Schard. Plant Cell Biotechnology and Molecular Biology 3\&4: 108-118.

Devendra NK, Subhash B andSeetharam YN (2009) Callus growth and plant regeneration in Momordica dioica (Roxb.) Willd. Cucurbitaceae. American-Eurasian Journal of Sustainable Agriculture 4: 743-8.

Dhanapal R, Chandanam S, Swamy V, VL AB, Gupta M and Basu SK (2006) Antisteroidogenic activity of Corallocarpus epigaeus Benth. ex Hook. tubers in female mice ovaries. Asian Journal of Chemistry 2: 94-98.

Dong JZ and Jia SR (1991) High efficiency plant regeneration from cotyledons of watermelon Citrullus vulgaris. Plant Cell Rep. 9(10): 559-62.

Doyle JJ and Doyle JL (1987) A rapid DNA isolation procedure for small quantities of fresh leaf tissue. Phytochem Bull. 19: 11-15.

Faisal M, Alatar AA, Hegazy AK, Alharbi SA, El-Sheikh M and Okla MK (2014) Thidiazuron induced in vitro multiplication of Mentha arvensis and evaluation of genetic stability by flow cytometry and molecular markers. Ind. Crops Prod. 62: 100-106.

Gnananath K, Reddy KR, Kumar GP, Krishna B, Reddy KS and Kumar AS (2013) Evaluation of antidiabetic activity in Corallocarpu sepigaeus rhizomes. International Current Pharmaceutical Journal. 1.2(3): 53-6.

Haque ME, Sarkar MA, Mahmud MA, Rezwana D and Sikdar B (2008) In vitro propagation of pumpkin and ash gourd through nodal segments. Journal of Bio-Science 16: 67-71.

He X, Xie D, Peng Q and Mu L (2006) Plant regeneration from cotyledon of CHIEK-QUA (Benincas ahispida Cogn. Var.). ISHS Acta Horticulture 764; XXVII. International Horticulture Conqress. International Symposium of Plant Biotechnology : From Bench to 764. pp. 225-230. 
Hesami M, Daneshvar MH, Yoosefzadeh-Najafabadi M and Alizadeh M (2018) Effect of plant growth regulators on indirect shoot organogenesis of Ficu sreligiosa through seedling derived petiole segments. Journal, Genetic Engineering \& Biotechnology 16(1): 175-180.

Hou J, Su P, Wang D, Chen X, Zhao, W and Wu L (2020) Efficient plant regeneration from in vitro leaves and petioles via shoot organogenesis in Sapium sebiferum Roxb. Plant Cell Tiss. Org. Cult.142: 143-156. https://doi.org/10.1007/s11240-020-01848-9.

Jeyaseelan M, Arumugam T and Thangaraj N (2014) Evaluation of antioxidant and antiinflammatory activities of Corallocarpu sepigaeus (Hook. F) rhizomes. Int. J. Pharm. Biomed Res. 591: $18-24$.

Kirubha TS, Senthamarai R, Vasuki K, Rao AV and Selvadurai S (2011) Anthelmintic activity of roots and rhizomes of Corallocarpu sepigaeus. J. Nat. Prod. Plant Resour. 1(1): 81-4.

Kothawade KA and Siddiqui AR (2018) A comprehensive review on pharmacological activity of Vernonia anthelmintica and Corallocarpus epigaeus. Asian Journal of Pharmaceutical Education and Research 7(2): 28-35.

Krishna DR and Shasthree T (2015) Adventitious rooting and proliferation from different explants of Citrulluscolocynthis (L.) Schrad an endangered medicinally important cucurbit. Asian Journal of Biotechnology 7(2):88-95.

Kumar HA, Murthy HN and Paek KY (2003) Embryogenesis and plant regeneration from anther cultures of Cucumis sativus L. Scientia Horticulturae. 98(3): 213-22.

Lakshmanan V, Reddampalli Venkataramareddy S and Neelwarne B (2007) Molecular analysis of genetic stability in long-term micropropagated shoots of banana using RAPD and ISSR markers. Electron J. Biotechnol. 10(1):106-113.

Mahesh R, Babu VS, Narayana MS, Naik DN and Malothu R (2012) Hepatoprotective activity of leaves of Corallocarpus epigaeus in carbon tetrachloride induced rats. Ramesh Malothu. et al International Journal of Biological and Pharmaceutical Research. 3(4): 567-70.

Narayan JP (2016) Ex situ conservation of the rare and threatened medicinal climber Corallocarpus epigaeus Rottler through in vitro regeneration method. Biotechnology Journal International 9: $1-10$.

Ozdemir FA andTürker M (2014) In vitro plant regeneration influence by BAP and IBA in lentils (Lens culinaris Medik). Journal of Applied Biological Sciences 8(1): 22-7.

Rajore Sand Batra A (2007) An alternative source for regenerable organogenic callus induction in Jatropha curcas L. Indian Journal of Biotechnology 6: 545-548.

Reshi NA, Sudarshana MS and Girish HV (2017) In vitro micropropagation of Anisochilus carnosus Wall. J. App. Pharm. Sci. 7(07): 098-102.

Sadhu S, Jogam P, Thampu RK, Abbagani S, Penna S and Peddaboina V (2020) High efficiency plant regeneration and genetic fidelity of regenerants by SCoT and ISSR markers in chickpea (Cicerarietinum L.). Plant Cell Tiss. Org Cult. 1-13.https://doi. org/10.1007/s11240-020-01804-7.

Saha S, H. Mori and K Hattori (2007) Synergistic effect of kinetin and benzyl adenine plays a vital role in high frequency regeneration from cotyledon explants of bottle gourd (Lagenaria siceraria) in relation to ethylene production. Breeding Science 15(7): 197-202.

Saranya U, Sivakanesan R and Varnakulendran N (2017) Evaluation of Haemopoietic Activity of the Rhizome of Corallocarpus epigaeus Benth. Ex Hook-A Pilot Study. Age. 20: $20: 50$ y. 
Shirin F and Rana PK (2007) In vitro plantlet regeneration from nodal explants of field grown culms in Bambusa glaucescens wild. Plant Biotechnology Reports. 8(7): 141-7.

Umadevi U and Kamalam M (2012) Pharmacognostical, phytochemical and heavy metal studies on an ethno medicinal plant- Corallocarpus epigaeus (Rottl. \&Wild.) Clarke 4(3): 117-121.

Uthrapathy S, Shabi MM, Krishnamoorthy G, Ravindhran D, Rajamanickam VG and Dubey GP (2011) Analgesic and anti-arthritic effect of Corallocarpusepigaeus. Acta Bioquímica Clínica Latinoamericana 45(4): 749-56.

Vemula S, Koppula T, Jogam P and Mohammed M (2020) In vitro high frequency multiplication and assessment of genetic fidelity of Corallocarpus epigaeus: An endangered medicinal plant. Vegetos.33(1):63-73.

Venkatachalam P, Jinu U, Sangeetha P, Geetha N andSahi SV (2018) High frequency plant regeneration from cotyledonary node explants of Cucumis sativus L. cultivar 'Green Long' via adventitious shoot organogenesis and assessment of genetic fidelity by RAPD-PCR technology. 3 Biotech. 8(1): 60-66.

(Manuscript received on 26 August, 2020; revised on 5 November, 2020) 